\title{
Performance of Glow Fixation GoCheck Kids and 2WIN Photoscreeners and Retinomax to Uncover
} Hyperopia

\author{
Alexa H Levitt ${ }^{\prime}$ \\ Samuel J Martin ${ }^{2}$ \\ Robert W Arnold (iD ${ }^{3}$ \\ 'Human and Organizational \\ Development, Vanderbilt University, \\ Nashville, TN, USA; ${ }^{2}$ Research \\ Department, Alaska Blind Child \\ Discovery, Anchorage, AK, USA; ${ }^{3}$ Alaska \\ Blind Child Discovery, Alaska Children's \\ EYE \& Strabismus, Anchorage, AK, USA
}

\section{Video Abstract}

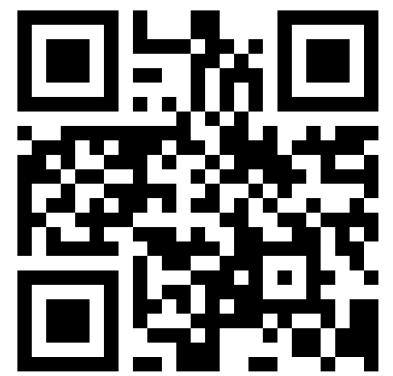

Point your SmartPhone at the code above. If you have a $Q R$ code reader the video abstract will appear. Or use: https://youtu.be/z-HV86x0y3M
Correspondence: Robert W Arnold Alaska Blind Child Discovery, Alaska Children's EYE \& Strabismus, Anchorage, AK, USA

Email eyedoc@alaska.net
This article was published in the following Dove Press journal: Clinical Ophthalmology

Background: A low-detail, glowing fixation device was added to GoCheck Kids (GCK) photoscreener in the hope of unmasking hyperopia and amblyopia risk factors (ARF).

Methods: Pediatric eye patients were screened by GCK and 2WIN photoscreeners, and Retinomax autorefractor before being compared to AAPOS ARFs.

Results: Screening was attempted by 131 children who then had school bus accommodation-relaxing skiascopy (SBA-RS) before cycloplegic examination. By 2013 AAPOS uniform guidelines, sensitivity/specificity for GCK was $87 \% / 68 \%$, for 2 WIN $87 \% / 71 \%$ and for Retinomax 79\%/68\%. Detection of amblyopia had sensitivity/specificity by GCK of $78 \%$ / $63 \%$, for 2 WIN $79 \% / 65 \%$ and for Retinomax $77 \% / 68 \%$. Inconclusive screens were seven for GCK, six for 2 WIN and 13 for Retinomax. Mean hyperopia for GCK $(+2.49 \pm 0.74 \mathrm{D})$ was similar to cycloplegic refraction $(+2.93 \pm 0.72 \mathrm{D})$ and SBA-RS $(+2.80 \pm 0.82 \mathrm{D})$ while GCK was slightly more than Retinomax $(+1.59 \pm 0.93 \mathrm{D}, p=0.13)$ but significantly more than $2 \mathrm{WIN}$ $(+1.02 \pm 0.49 \mathrm{D}, \mathrm{p}<0.01)$.

Conclusion: GCK, 2WIN and Retinomax had similar validity detecting uniform amblyopia risk factors and amblyopia itself. The nondetailed glow fixation device allowed GCK to uncover substantial hyperopia while the detailed flashing fixation devices on 2 WIN and Retinomax seemed to stimulate accommodation in some hyperopic children.

Clinical Trials Registry: NCT04297969. Data Access: http://www.abcd-vision.org/refer ences/GCK\%20glow\%202WIN\%20deidentify.pdf.

Précis: A glow fixation device on a smart phone photoscreener allowed robust detection of hyperopia.

Keywords: amblyopia risk factor, vision screening, photoscreener, hyperopia

\section{Introduction}

Amblyopia, a common treatable form of pediatric blindness, is caused by impaired brain learning of clear vision due to certain amblyopia risk factors (ARF). ${ }^{1}$ In $2003,{ }^{2}$ and again in $2013,{ }^{3}$ the vision screening committee of the American Association for Pediatric Ophthalmology and Strabismus (AAPOS) published uniform guidelines for target levels of amblyopia risk factors; cataract, strabismus, and certain levels of refractive error.

Hyperopia is demonstrated by most children after cycloplegia. Due to youth-related robust accommodation, most children resolve clear images by compensating for their level of hyperopia with sufficient accommodation. ${ }^{4}$ Excess hyperopia, usually more than +3.50 diopters can produce amblyopia if the child does not sufficiently 
accommodate, ${ }^{5}$ or if the excess accommodation produces esotropia. ${ }^{6,7}$ Photoscreeners attempt to identify children at risk for amblyopia by uncovering excess hyperopia and/or esotropia. Several different photoscreener methods of eliciting fixation and/or accommodation have been utilized by different manufacturers.

Smart phones have been adapted to perform photoscreening by GoCheck Kids (GCK, Phoenix, Ariz) resulting in consistent validity ${ }^{8}$ and a high positive predictive value (PPV) in pediatrician screening between $70 \%$ and $80 \%{ }^{9}$ The iPhone model $7+$ provides quality red reflex images, but even clearer and quicker when fitted with a flashconcentrating case. ${ }^{10}$ The latest version of GoCheck Kids places a nondetailed, colorful, slowly changing glowing fixation light near the camera lens.

Hyperopia and refractive error can also be estimated with the infrared photoscreener 2WIN (Adaptica, Padova Italy) and the handheld autorefractor Retinomax (Righton, Tokyo Japan). ${ }^{11}$ This study in children determines the ability of the GCK smart phone photoscreener with Glow fixation to estimate amblyopia refractive error risk factors, and particularly hyperopia compared to $2 \mathrm{WIN}$ and Retinomax.

\section{Methods}

The Alaska Blind Child Discovery evaluation of clinical test (Clinical Trials NCT04297969) study was approved by the Providence Institutional Review Board and is consistent with the Declaration of Helsinki (7th version 2013) and the Health Insurance Portability and Accountability Act. Patients were recruited from October through November 2019. Parents provided written informed consent and de-identified data are provided on the study website: http://www.abcd-vision.org/references/GCK\% 20glow\%202WIN\%20deidentify.pdf.

As a part of new and follow-up comprehensive pediatric ophthalmology examinations, and before cycloplegic refraction, patients were screened with objective devices and also had dry retinoscopy with the school bus accommodation-relaxing skiascopy (SBA-RS). ${ }^{12}$ The SBA-RS is a child-friendly handle with ten, adjacent convex integer diopter plus lenses held horizontally so the higher power fogs the patient to uncover hyperopia in the retinoscoped eye. Each had photoscreening with the GoCheck Kids iPhone 7+ smart phone with flash-concentrating case modified with a battery-powered, nondetailed colored, glowing fixation device $33 \mathrm{~mm}$ in diameter centered $38 \mathrm{~mm}$ below the camera (devices shown in Figure 1). The flash- concentrating case places a high convex lens in front of the iPhone "flash" so the wide angle illumination is concentrated on the subject's face. The GoCheck Kids screenings were internet transferred to be expert centrally manually interpreted. GoCheck Kids claims to be prepared to update to newer phones when needed. The primary outcome was comparison of ability to uncover spherical equivalent hyperopia compared to cycloplegia. The secondary analysis was validation compared to AAPOS uniform refractive amblyopia risk factors (ARF).

Patients less than eight years old were included whose parents signed informed consent, and were able to participate with fixating on the screening devices in addition to having complete exam with cycloplegic retinoscopy 30 minutes after cyclopentolate $1 \%$. Additional pediatric patients with hyperopia were also invited to participate. We included patients with developmental delay since these often are of particular interest to pediatricians and pediatric ophthalmologists. Excluded were patients too young or inattentive to fix on the photoscreeners or patients with anterior segment or posterior pole dysmorphology. Characteristics of patients are shown in Table 1.

Patients also had screening with the 2 WIN infrared photoscreener ( $\mathrm{v}$ 5.0171,018) and an age-matched subset of 61 patients also attempted screening with the Retinomax K plus 3 autorefractor. Table 1 shows ages and gender mix of patients able to complete refractive screening. The Kaleidos external case was not employed for this study but the bright twinkling colored LED fixation light function was selected. ${ }^{10}$ Validation was based on refractive amblyopia risk factors defined by AAPOS $2003^{2}$

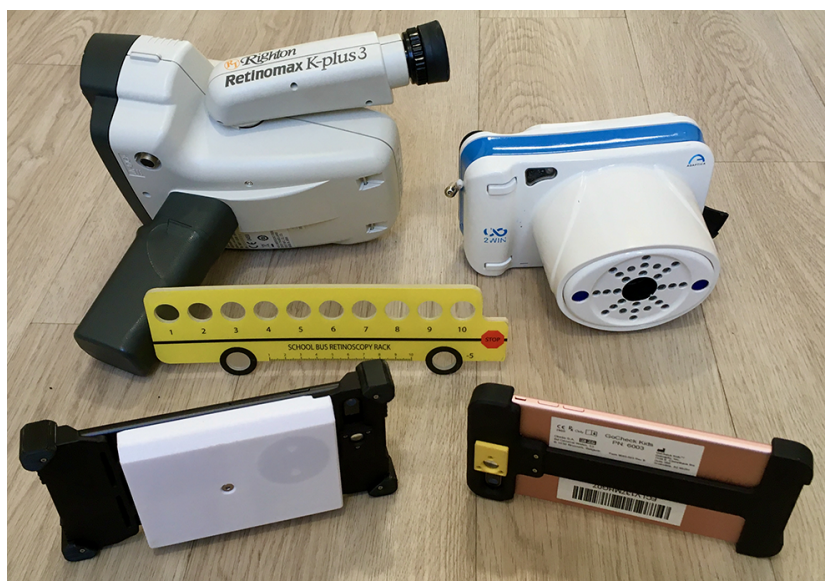

Figure I Three vision screening devices. GoCheck Kids (GCK) with flash concentrating case (foreground right) and a second GCK modified with white box containing the nondetailed slowly changing glow fixation device (foreground left). In the background left is the Righton Retinomax, on the right Adaptica 2WIN and center the school bus accommodation-relaxing skiascopy. 
Table I Breakdown of Gender and Ages (Years) of Patients who Successfully Completed Each Refractive Screening. Most of the Patients who were not able to complete Retinomax were younger

\begin{tabular}{|l|l|l|l|l|l|l|}
\hline Technique & Total & Females & Median Age & Quartile I & Quartile 3 & Mean \pm SD \\
\hline GCK & 131 & 59 & 5.9 & 3.7 & 9.1 & $6.8 \pm 4.4$ \\
2WIN & 125 & 55 & 6.0 & 3.7 & 9.1 & $6.8 \pm 4.4$ \\
Retinomax & 48 & 24 & 8.2 & 6.0 & 12.8 & $9.4 \pm 4.3$ \\
SBA-RS & 113 & 52 & 6.0 & 3.7 & 9.1 & $6.8 \pm 4.4$ \\
\hline
\end{tabular}

Table 2 AAPOS Confirmatory Cycloplegic Exam Uniform Guidelines for Refractive Amblyopia Risk Factors. ${ }^{2,3}$ Anisometropia Spherical or Cylindrical

\begin{tabular}{|l|l|l|l|l|}
\hline Guideline/Age & Anisometropia & Hyperopia & Astigmatism & Myopia \\
\hline $201312-30 \mathrm{mo}$ & $>2.5 \mathrm{D}$ & $>4.5 \mathrm{D}$ & $>2.5 \mathrm{D}$ & 3 or more \\
$201331-48 \mathrm{mo}$ & $>2.0 \mathrm{D}$ & $>4.0 \mathrm{D}$ & $>2.0 \mathrm{D}$ & 3 or more \\
$201349-72 \mathrm{mo}$ & $>1.5 \mathrm{D}$ & $>3.5 \mathrm{D}$ & $>1.5 \mathrm{D}$ & 3 or more \\
2003 preschool & $>1.5 \mathrm{D}$ & $>3.5 \mathrm{D}$ & $>1.5 \mathrm{D} *$ & 3 or more \\
\hline
\end{tabular}

Note: $* 2003$ astigmatism oblique more than $10^{\circ}$ of vertical and horizontal meridia $>1.0 \mathrm{D}$.

and also age-stratified $2013^{3}$ uniform guidelines. Hyperopia was defined as any patient with a cycloplegic spherical equivalent greater than or equal to $+0.50 \mathrm{D}$. The degree of hyperopia was compared with independent samples, Student's $t$-test and Mann-Whitney $U$-test with $p<0.05$ considered significant. Bland-Altman analysis ${ }^{13}$ of the patients with cycloplegic hyperopia $>0.50$ D compared to each photoscreener, the Retinomax and SBA-RS was done.
Sample size calculation: with power 0.8 and alpha 0.05 , to determine a difference of 1.0 given standard deviation 1.5 a sample size of 36 is needed. To determine 0.7 difference with standard deviation of 2.0 , the sample size would be 129 .

\section{Results}

GCK photoscreening and cycloplegic exams were completed on 131 patients, median age 5.9 years, interquartile 3.7 to 9.1

Table 3 Validation Table for Three Objective Vision Screening Devices Using AAPOS Uniform Criteria

\begin{tabular}{|c|c|c|c|c|c|c|c|c|c|c|}
\hline \multirow[t]{5}{*}{ Exam Criteria } & \multirow[t]{5}{*}{ Device } & & $X+$ & $\mathbf{X}-$ & \multirow[t]{5}{*}{ D } & \multirow[t]{5}{*}{$\mathbf{E}$} & \multirow[t]{5}{*}{$\mathbf{F}$} & \multirow[t]{4}{*}{$\mathbf{i}=$ refer } & \multirow[t]{5}{*}{ Specificity } & \multirow[t]{5}{*}{ PPV } \\
\hline & & sct & $\mathbf{A}$ & B & & & & & & \\
\hline & & sc- & C & D & & & & & & \\
\hline & & sci & $\mathbf{E}$ & $\mathbf{F}$ & & & & & & \\
\hline & & $\mathbf{A}$ & B & C & & & & Sensitivity & & \\
\hline \multirow[t]{3}{*}{2013} & GCK glow & 51 & 18 & 8 & 47 & 3 & 4 & $87 \%$ & $68 \%$ & $71 \%$ \\
\hline & $2 \mathrm{WIN}$ & 50 & 18 & 8 & 49 & 4 & 2 & $87 \%$ & $71 \%$ & $73 \%$ \\
\hline & Retinomax & 25 & 7 & 1 & 15 & 6 & 7 & $79 \%$ & $68 \%$ & $82 \%$ \\
\hline \multirow[t]{3}{*}{2003} & GCK glow & 46 & 23 & 7 & 48 & 4 & 3 & $88 \%$ & $65 \%$ & $66 \%$ \\
\hline & $2 \mathrm{WIN}$ & 47 & 21 & 6 & 51 & 4 & 2 & $89 \%$ & $69 \%$ & $69 \%$ \\
\hline & Retinomax & 22 & 10 & I & 15 & 6 & 7 & $78 \%$ & $60 \%$ & $74 \%$ \\
\hline \multirow[t]{3}{*}{ Amblyopia } & GCK glow & 42 & 27 & 9 & 46 & 3 & 4 & $78 \%$ & $63 \%$ & $63 \%$ \\
\hline & $2 \mathrm{WIN}$ & 42 & 26 & 9 & 48 & 3 & 3 & $79 \%$ & $65 \%$ & $63 \%$ \\
\hline & Retinomax & 25 & 7 & I & 15 & 5 & 8 & $77 \%$ & $68 \%$ & $81 \%$ \\
\hline
\end{tabular}

Notes: The GoCheck Kids iPhone 7+ smartphone with flash concentrating case with nonaccommodative glow fixation (GCK glow), the Adaptica 2 WIN infrared photoscreener and (on select patients) the Righton Retinomax are compared in a high prevalence cohort of children. A $3 \dot{\times} 2$ validation compares those with screen refer (sc + ), screen pass (sc-) and screen inconclusive (sci) compared to those who met exam criteria $(X+)$ and those who did not exceed exam criteria $(X-)$. The gold standard exam criteria were either uniform guideline American Association for Pediatric Ophthalmology and Strabismus (AAPOS) age-stratified published in 2013, non-age-stratified published in 2003, or amblyopia defined as visual acuity $20 / 40$ or worse with amblyopia risk factors (ARF). Inconclusive screenings are regarded as referrals $(i=$ refer). 


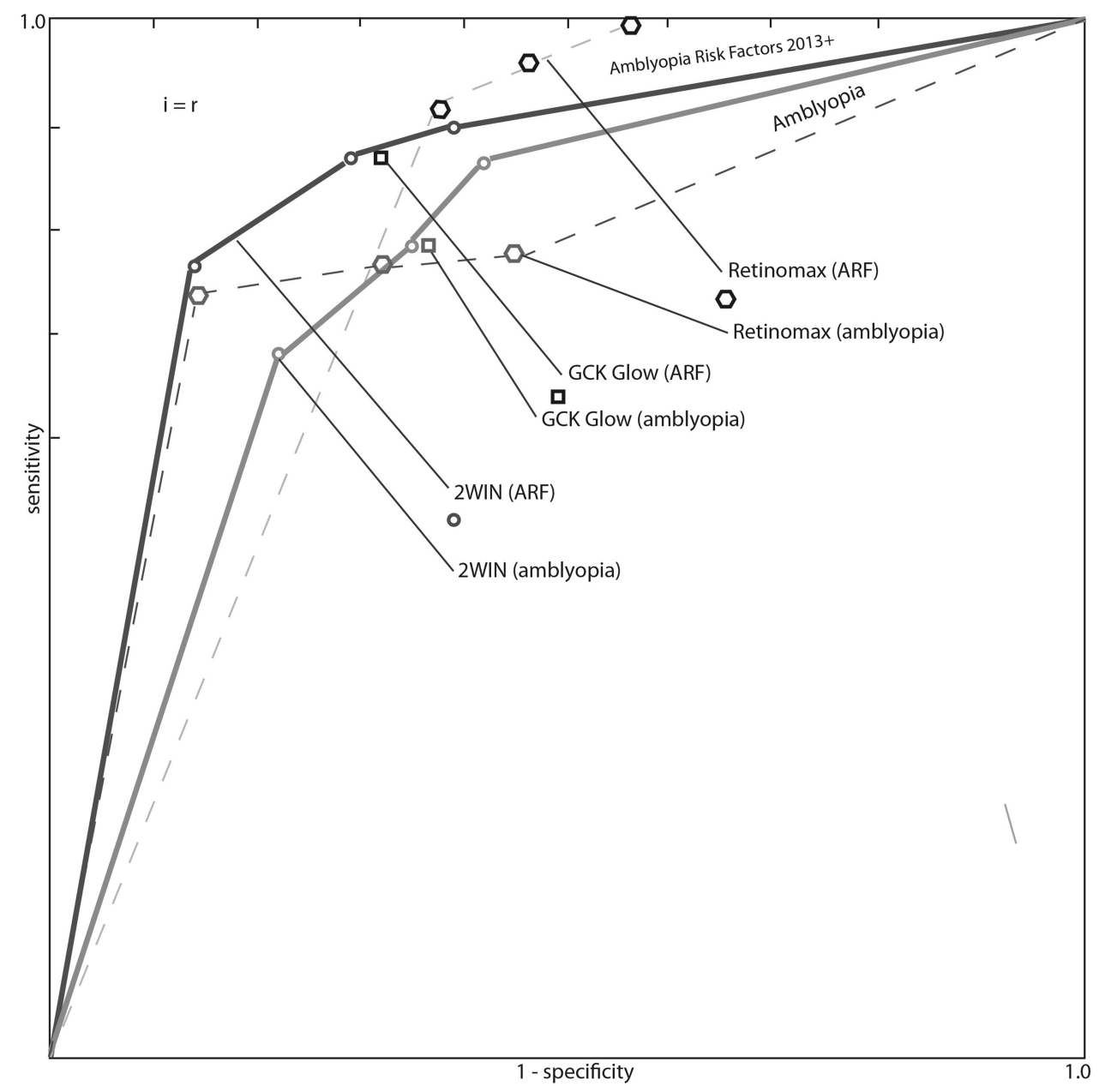

Figure 2 ROC curve for three objective vision screeners. Receiver operating characteristic (ROC) curve showing GoCheck Kids iPhone 7+ in flash concentrating case with glow fixation device (GCK), the Adaptica $2 \mathrm{WIN}$ and the Retinomax.

years, range 0.1 to 18 years. Race and ethnicity were Caucasian 75, Pacific Islander 17, Black 14, Hispanic 14, Alaska Native 6 and Asian 5. Twenty-two were referred by photoscreening and 16 had developmental delays including autism and Down syndrome. The prevalence of 2003 AAPOS risk factors (Table 2) was $44 \%$ and the 2013 risk factor prevalence was $47 \%$. There were seven inconclusive screenings (patient did not fix on device, or no interpretation) from GCK, six inconclusive with 2WIN and 13 with Retinomax; inconclusive results were considered as referrals.

Table 3 gives $2 \dot{\times} 3$ validation metrics showing the three devices compared against three uniform standards 2003 and 2013 AAPOS risk factors and amblyopia defined as acuity $20 / 40$ or worse with ARF or two-line, inter-eye difference. A receiver operating characteristic (ROC) curve for AAPOS risk factors comparing GoCheck Kids with glow fixation to 2 WIN is shown in Figure 2. Using AAPOS 2013 uniform guidelines, the sensitivity/
specificity/PPV for GCK glow fixation was $87 \% / 68 \%$ / $71 \%$, for 2 WIN $87 \% / 71 \% / 73 \%$ and for Retinomax $79 \% /$ $68 \% / 82 \%$.

The range of hyperopia estimation for noncycloplegic GCK glow fixation, 2WIN and Retinomax are compared to school bus accommodation-relaxing skiascopy (dry) and cycloplegic retinoscopy in Figure 3. Mean \pm SD for cycloplegic refraction was $+2.93 \pm 0.72$, for SBA-RS $+2.80 \pm 0.82$, for GCK $+2.49 \pm 0.74$, for Retinomax $+1.59 \pm 0.93$ and for 2 WIN $+1.02 \pm 0.49$ diopters. For cycloplegic refraction and spherical equivalent, skewness was -0.4 and Kurtosis 3.5 , but for hyperopia skewness was 0.7 and Kurtosis was -1 . The distribution of hyperopic refractions was less normally distributed than all refractions, therefore nonparametric statistics were also employed. Figure 4 shows Bland-Altmann plots comparing the screening devices and SBA-RS to cycloplegic refraction for hyperopic patients. Table 4 shows statistical comparison of means and medians for distributions of 


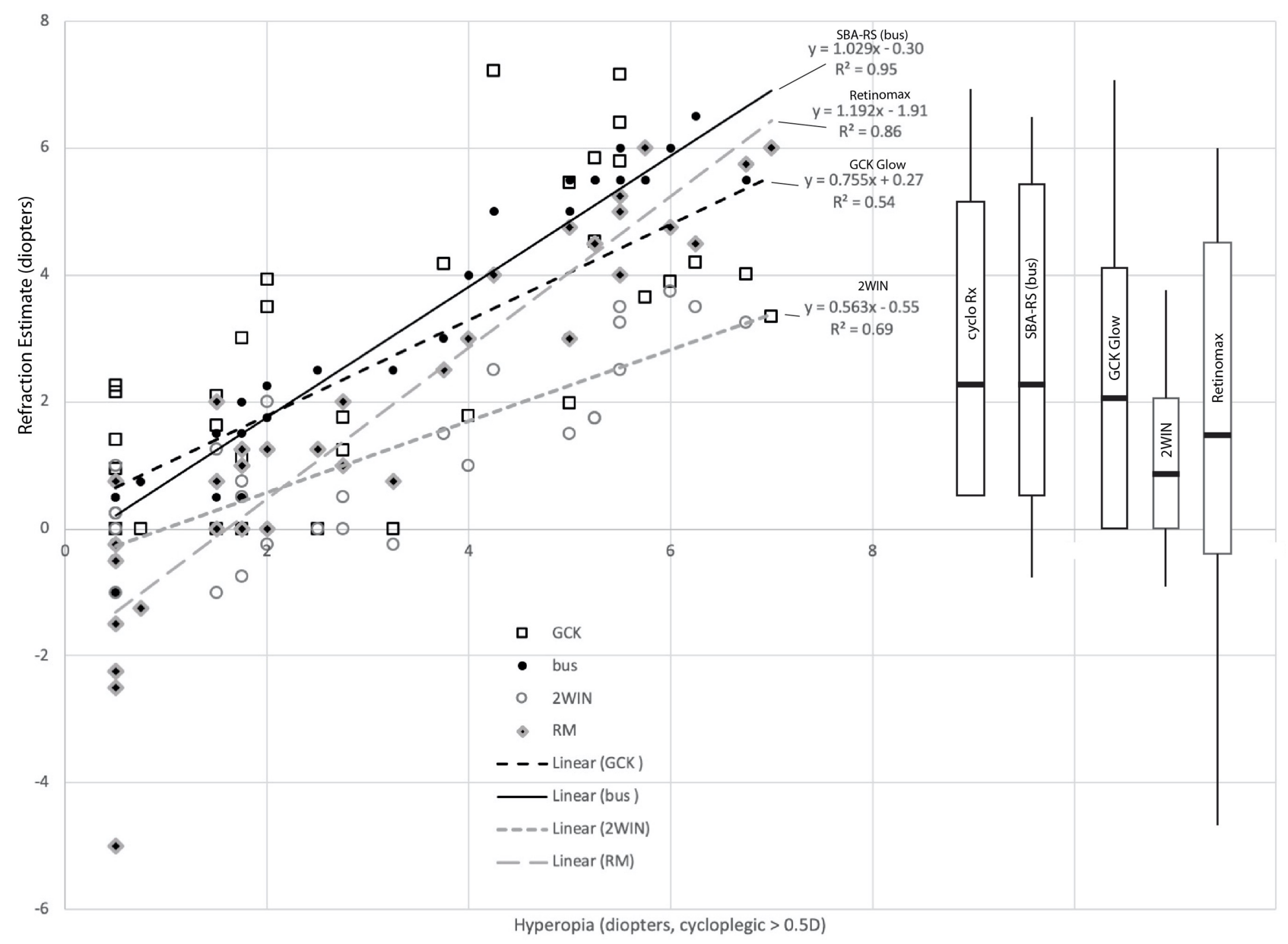

Figure 3 Hyperopia detected by photoscreeners. Linear correlations for the three vision screen devices, GoCheck Kids with glow fixation (GCK), Adaptica 2WIN and Retinomax (RM) and school bus accommodation-relaxing skiascopy (bus) compared to spherical equivalent cycloplegic refraction on left side of graph. On right side of graph, whisker plots demonstrate the degree of hyperopia measured by each technique with boxes encompassing the $25 \%$ and $75 \%$ with central horizontal bar the median and vertical bars extending to the range.

estimated hyperopia by the three devices compared to cycloplegic exam and school bus accommodation-relaxing skiascopy (SBA-RS). ${ }^{12}$

\section{Discussion}

Smart phones, owing to their inherent photographic "design flaw" from the close proximity between flash and lens, have the potential to produce very practical photorefractive pupillary red reflexes. External cases can enhance performance of photoscreeners. ${ }^{10}$ In this study, an iPhone $7+$ smartphone in a performance-enhancing case performed very similarly to state-of-the-art infrared photorefractor and a handheld Safir-method autorefractor in the detection of amblyopia and refractive amblyopia risk factors. ${ }^{14}$ To uncover hyperopia similar to the cycloplegic refraction in children we found 2 WIN with sparkling fixation least, then Retinomax and then the GoCheck Kids with glow fixation and finally noncycloplegic school bus accommodation-relaxing skiascopy.

We had some inconclusive results from both photoscreeners and the Retinomax. Young and developmentally challenged patients seemed to be intimidated with the facial proximity of Retinomax leading to a higher inconclusive rate than GCK or 2 WIN. The ongoing glowing fixation light on GoCheck kids was so intriguing to some children that they wanted to grab it; screening might be thus less interrupted if the screener could activate and deactivate the glow fixation light when screening was completed.

The Adaptica 2WIN is a capable photoscreening performance resembling the other infrared devices. ${ }^{15}$ 2 WIN has the option to activate fixation lights and sounds or disable them during photoscreening. We chose to use both sound and twinkling lights, alternating 


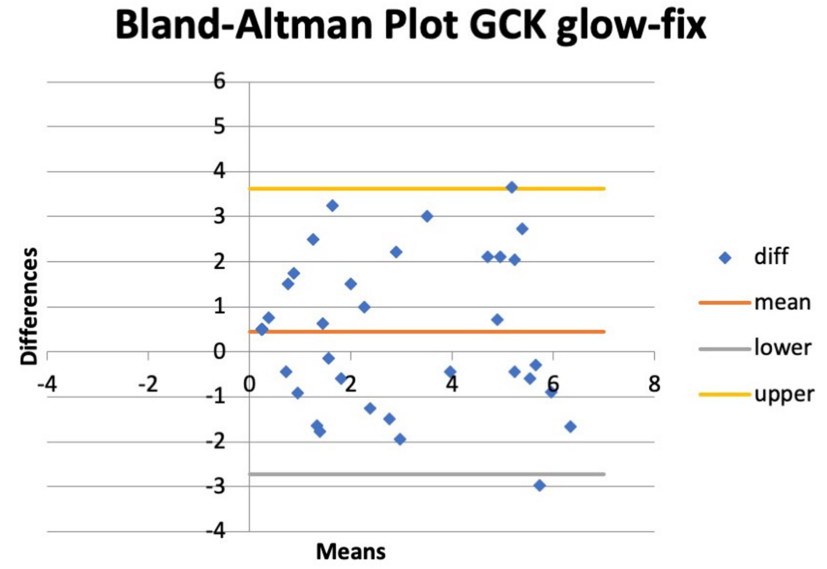

\section{Bland-Altman Plot Retinomax}

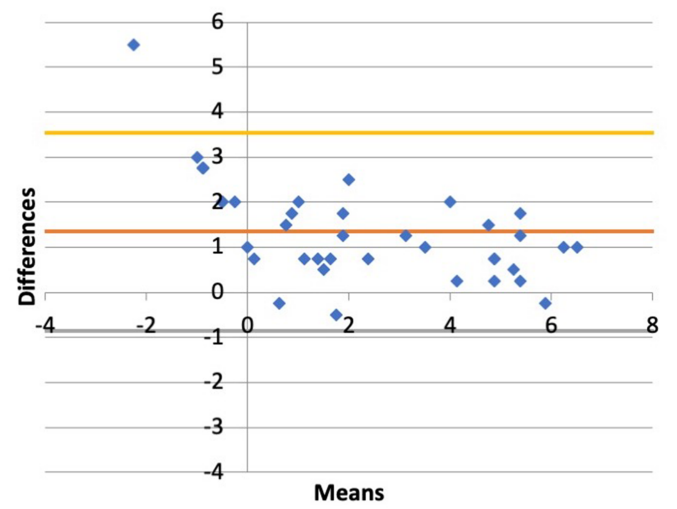

Bland-Altman Plot 2WIN

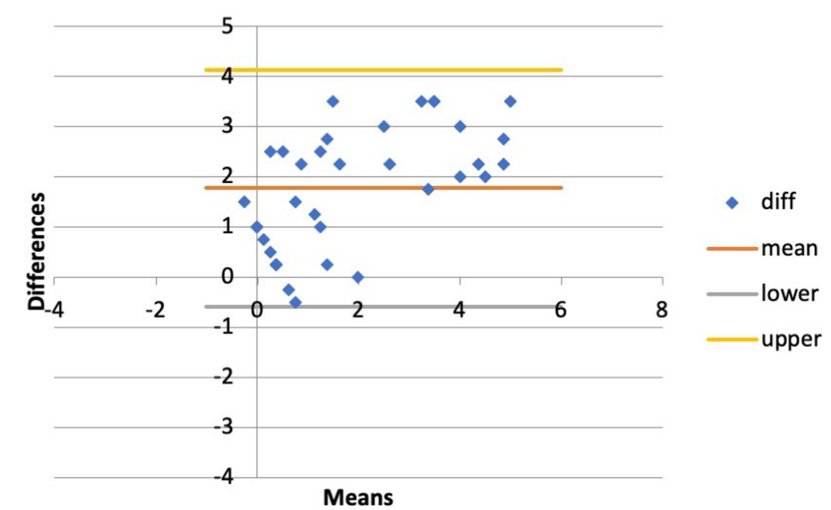

Bland-Altman Plot SBA-RS

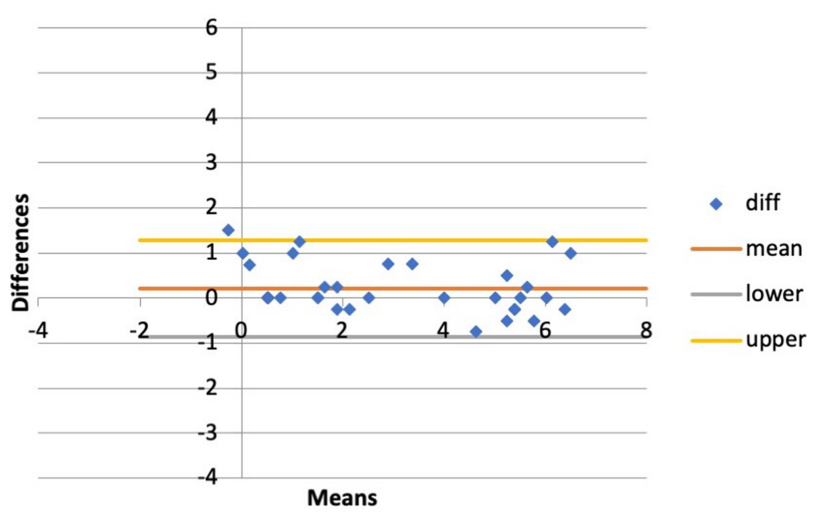

Figure 4 Bland-Altmann Plot analysis comparing cycloplegic refraction to two photoscreeners (GoCheck Kids (GCK) with glow fixation and Adaptica 2WIN) and Retinomax remote autorefractor and school bus accommodation-relaxing skiascopy (SBA-RS). These patients all had a spherical equivalent of $0.5 \mathrm{D}$ or greater hyperopia with cycloplegic refraction. Each patient had readings with all four compared screening modalities.

colorful LEDs around the lens effectively promotes accommodation during photoscreening. We suspect that a few children would not engage in 2WIN fixation without the bright flashing lights, but we may also uncover more hyperopia if less fixation stimulus is selected with 2 WIN.

Table 4 Differences Between Estimates of Hyperopia for Three Vision Screen Devices

\begin{tabular}{|c|c|c|c|c|}
\hline$t$-Test $(p)$ & Bus & GCK & RM & 2 WIN \\
\hline Cyclo & $0.25(0.8)$ & $0.88(0.38)$ & $2.33(0.02)$ & $4.28(<0.01)$ \\
\hline Bus & & $0.58(0.57)$ & $1.98(0.05)$ & $3.80(<0.01)$ \\
\hline GCK & & & $1.54(0.13)$ & $3.32(<0.01)$ \\
\hline RM & & & & I.07 (0.29) \\
\hline \multicolumn{5}{|c|}{ Mann-Whitney $(p)$} \\
\hline & Bus & GCK & RM & 2 WIN \\
\hline Cyclo & $635(1.00)$ & $616(<0.01)$ & $524(<0.01)$ & $314(<0.01)$ \\
\hline Bus & & $601(1.00)$ & $498(<0.0 \mathrm{I})$ & $343(0.10)$ \\
\hline GCK & & & $600(<0.01)$ & $405(<0.01)$ \\
\hline RM & & & & $571(1.00)$ \\
\hline
\end{tabular}

Notes: The difference between means with $p$ values in parentheses analyzed by $t$-test (upper table) and the difference between medians determined by Mann-Whitney U. Intersecting comparisons for vision screeners GoCheck Kids with flash concentrating case with glow fixation (GCK), Adaptica 2WIN and Retinomax (RM) compared to cycloplegic refraction (cyclo) and school bus accommodation-relaxing skiascopy (SBA-RS or bus). 
Retinomax for fixation presents an image of a flower against a colorful green grass and blue sky background for sequential, handheld, monocular Safir autorefraction. Though lenses attempt to make the flower image appear at a distance, young viewers often accommodate in part because they sense the image is created just a few centimeters from their eye. It is quite possible to have robust and asymmetric accommodation with Retinomax which is apparent in Figure 2 and the BlandAltman plot. Retinomax has been used as a uniform, gold standard in determination of refractive error following cycloplegia in the landmark MEPEDS ${ }^{16}$ and BPEDS ${ }^{17}$ population studies. Another recent study from Los Angeles utilized the Retinomax without cycloplegia as a screener ${ }^{18}$ uncovering only $1 \%$ amblyopia when MEPEDS would have predicted $2.5 \%$. Compared to cycloplegic refraction in hyperopic patients, dry school bus accommodation-relaxing skiascopy uncovered hyperopia $95 \%$, GoCheck Kids with glow fixation $85 \%$, Retinomax $54 \%$ and 2 WIN with active LED fixation just $35 \%$. This compares to another study in which Retinomax uncovered less noncycloplegic hyperopia than SBA-RS. ${ }^{12}$ When flash concentrating iPhone 7+ GoCheck Kids was compared to $2 \mathrm{WIN}$ in Kaleidos case, The Kaleidos has sensitivity $87 \%$, specificity $84 \%$ while GCK had sensitivity $85 \%$ and specificity $73 \%$ using 2003 AAPOS guidelines. ${ }^{10}$

High hyperopia is a risk factor for amblyopia, and it is advised to determine the full amount. ${ }^{19}$ However, many children accommodate for high hyperopia sufficiently to not develop amblyopia. ${ }^{20}$ The Alaska Blind Child Discovery promotes the theory that insufficiently accommodated hyperopia is a more profound amblyopia risk factor than high (cycloplegic) hyperopia alone. Deficiencies in accommodation can be estimated by the Grand Seiko open field autorefractor. ${ }^{21,22}$ As such, stimulating accommodation and referring only those who persist with latent hyperopia may reduce false positive vision screening particularly in remote areas like Alaska where vision screen follow-up can be expensive and daunting.

Study strengths include simultaneous comparison of different fixation devices in different objective screening devices on an ethnically diverse group of children. Since we did not exclude children with developmental delay, the results are more generalizable to pediatric screening of these patients for whom objective screening is helpful even at older ages than photoscreening is traditionally recommended. A relative weakness of our study was that the Retinomax was not available for a portion of the patients and some of the patients were older than eight years of age. This was a high risk, high prescreening prevalence cohort, and repeated study in a normal risk population would be instructive.

\section{Conclusion}

The glowing fixation device seems to allow GoCheck Kids to uncover a high degree of the amblyopia risk factor hyperopia. High yield, early portable screening with such devices holds promise in reducing the burden of amblyopia vision impairment.

\section{Disclosure}

Miss Alexa Levitt reports grants from Ingram Scholars Program, during the conduct of the study; in addition, Miss Alexa Levitt has a patent glowing fixation device pending; and at the time this study was conducted she was an intern at GoCheck and finishing her undergraduate degree at Vanderbilt University. The Ingram Scholars Program (undergraduate merit scholarship program) awarded her the necessary funding to support her travel expenses from Nashville, TN (where the GoCheck office is) to Anchorage, $\mathrm{AK}$ (where Alaska Blind Child Discovery is). She worked with Dr Robert Arnold in his clinic on behalf of the Clinical team at GoCheck. Dr Arnold is a board member of Glacier Medical Software and PDI Check. He coordinates the Alaska Blind Child Discovery project and is an unpaid member of an advisory board to several photoscreeners including GoCheck Kids and Adaptica. Dr Arnold is an investigator and protocol developer with the NIH-supported Pediatric Eye Disease Investigator Group. Dr Arnold is a nonpaid advisory board member for PlusoptiX and iScreen, during the conduct of the study. He coordinates remote medical mission outreach that has received donations from several vendors for Burma Vision, outside the submitted work. In addition, Dr Robert W Arnold has a patent PDI Check pending to Robert W. Arnold and Alex Damarjian. The authors report no other conflicts of interest in this work.

\section{References}

1. Wallace DK, Repka MX, Lee KA, et al. Amblyopia preferred practice pattern(R). Ophthalmology. 2018;125:P105-P142. doi:10.1016/j. ophtha.2017.10.008

2. Donahue S, Arnold R, Ruben JB. Preschool vision screening: what should we be detecting and how should we report it? Uniform guidelines for reporting results of preschool vision screening studies. J AAPOS. 2003;7(5):314-316. doi:10.1016/S1091-8531(03)00182-4

3. Donahue SP, Arthur B, Neely DE, Arnold RW, Silbert D, Ruben JB. Guidelines for automated preschool vision screening: a 10-year, evidence-based update. J AAPOS. 2013;17(1):4-8. doi:10.1016/j. jaapos.2012.09.012 
4. Tarczy-Hornoch K. Accommodative lag and refractive error in infants and toddlers. J AAPOS. 2012;16(2):112-117. doi:10.1016/j. jaapos.2011.10.015

5. Horwood AM, Riddell PM. Hypo-accommodation responses in hypermetropic infants and children. Br J Ophthalmol. 2011;95 (2):231-237. doi:10.1136/bjo.2009.177378

6. Somer D, Karabulut E, Cinar FG, Altiparmak UE, Unlu N. Emmetropization, visual acuity, and strabismus outcomes among hyperopic infants followed with partial hyperopic corrections given in accordance with dynamic retinoscopy. Eye. 2014;28 (10):1165-1173. doi:10.1038/eye.2014.161

7. Somer D, Karabulut E, Cinar FG, Altiparmak UE, Unlu N. The role of dynamic retinoscopy in predicting infantile accommodative esotropia and influencing emmetropization. J Binocul Vis Ocul Motil. 2018;68:54-58. doi:10.1080/2576117X.2018.1468685

8. Arnold RW, O'Neil JW, Cooper KL, Silbert DI, Donahue SP. Evaluation of a smartphone photoscreener app to detect refractive amblyopia risk factors in children 1-6 years. Clin Ophthalmol. 2018;12:1533-1537. doi:10.2147/OPTH.S171935

9. Arnold RW, Arnold AW, Hunt-Smith TT, Grendahl RL, Winkle RK. The positive predictive value of smartphone photoscreening in pediatric practices. J Pediatr Ophthalmol Strabismus. 2018;55(6):39 3-396. doi:10.3928/01913913-20180710-01

10. Martin SJ, Htoo HE, Hser N, Arnold RW. Performance of two photoscreeners enhanced by protective containers. Clin Ophthalmol. 2020;14:1427-1435. doi:10.2147/OPTH.S251451

11. Racano E, Alessi S, Pertile R. Comparison of 2 Win and plusoptiX A12R refractometers with retinomax handheld autorefractor keratometer. J AAPOS. 2019;23(5):276 e1-e5. doi:10.1016/j.jaapos. 2019.05.017

12. Arnold AW, Arnold SL, Sprano JH, Arnold RW. School bus accommodation-relaxing skiascopy. Clin Ophthalmol. 2019;13:18 41-1851. doi:10.2147/OPTH.S219031

13. Bland JM, Altman DG. Statistical methods for assessing agreement between two methods of clinical measurement. Lancet. 1986;327 (8476):307-310. doi:10.1016/S0140-6736(86)90837-8
14. Safir A, Kulikowski C, Deuschle K. Automatic refraction: how it is done: some clinical results. Sight Sav Rev. 1973;43(3):137-148.

15. Kirk S, Armitage MD, Dunn S, Arnold RW. Calibration and validation of the 2WIN photoscreener compared to the PlusoptiX S12 and the SPOT. J Pediatr Ophthalmol Strabismus. 2014;51(5):1-4. doi:10.3928/01913913-20140701-01

16. MEPEDS, Borchert M, Wang Y, Tarczy-Hornoch K, et al. Testability of the retinomax autorefractor and IOLMaster in preschool children: the Multi-ethnic Pediatric Eye Disease Study. Ophthalmology. 2008;115(8):1422-5, 5 e1. doi:10.1016/j.ophtha.2007.10.036

17. Giordano L, Friedman DS, Repka MX, et al. Prevalence of refractive error among preschool children in an urban population: the Baltimore Pediatric Eye Disease Study. Ophthalmology. 2009;116(4):739-46, 46 e1-4. doi:10.1016/j.ophtha.2008.12.030

18. Margines JB, Huang C, Young A, et al. Refractive errors and amblyopia among children screened by the UCLA preschool vision program in Los Angeles County. Am J Ophthalmol. 2020;210:78-85. doi:10.1016/j.ajo.2019.10.013

19. Wallace DK, Morse CL, Melia M, et al. Pediatric eye evaluations preferred practice pattern(R): I. Vision screening in the primary care and community setting; II. Comprehensive ophthalmic examination. Ophthalmology. 2018;125:P184-P227. doi:10.1016/j.ophtha.2017.09.032

20. Arnold RW. Amblyopia risk factor prevalence. J Pediatr Ophthalmol Strabismus. 2013;50(4):213-217. doi:10.3928/01913913-20130326-01

21. Singman E, Matta N, Tian J, Silbert D. Association between accommodative amplitudes and amblyopia. Strabismus. 2013;21 (2):137-139. doi:10.3109/09273972.2013.786737

22. Matta NS, Singman EL, Brubaker C, Silbert DI. Auto-objective accommodative measurements as a valid and reliable new method of pediatric, strabismus and amblyopia, vision screening. Binocul Vis Strabolog $Q$ Simms Romano. 2011;26:140-145.
Clinical Ophthalmology

\section{Publish your work in this journal}

Clinical Ophthalmology is an international, peer-reviewed journal covering all subspecialties within ophthalmology. Key topics include: Optometry; Visual science; Pharmacology and drug therapy in eye diseases; Basic Sciences; Primary and Secondary eye care; Patient Safety and Quality of Care Improvements. This journal is indexed on PubMed

\section{Dovepress}

Central and CAS, and is the official journal of The Society of Clinical Ophthalmology (SCO). The manuscript management system is completely online and includes a very quick and fair peer-review system, which is all easy to use. Visit http://www.dovepress.com/ testimonials.php to read real quotes from published authors. 